THE

\title{
Journal
}

on

\section{Nervous and Mental Disease}

\section{AMERICAN NEUROLOGICAL ASSOCIATION.}

Treenty-third Annual Meeting, held at St. Fohn's Parish Hall Washington, D.C., May $4 t h$, 5 th, and $6 t h, 1897$.

The President, Dr. M. A. Starr, in the chair.

\section{LITTLE'S DISEASE; SHALL WE RETAIN THE NAME?}

By B. SACHS, M.D.,

Professor of Mental aud Nervous Diseases in the New York Polycliuic, etc.

The various types of cerebral spastic palsies in children have received so much attention during the past five or six years that it might seem quite superfluous to continue the discussion of them; but the subject is one that grows from year to year. Few diseases of the central nervous system have presented as many puzzling problems. Freud's masterly monograph, ${ }^{1}$ exhaustive yet not prolix, is the best evidence of the importance to which these various types of disease have attained. On the majority of points under discussion a unanimity of opinion has been established, but of late German and French anthors have created some confusion by insisting that Little's disease shall be recognized as a distinct clinical entity. At the same time

${ }^{1}$ Die Infantile Cerebralläbmung, von Dr. Sigm. Freud. Nothnagel's Specielle Pathologie, etc., Band IX. Vienna, I897. 
English and American writers are taunted with the remark that they appear to have remained in ignorance of Little's views, though they might have been expected to have known them far better than the Continental authors of the day. One of the latest German authors, ${ }^{2}$ states that "English and American authors make no distinction between Little's disease and double cerebral palsies; little do they care whether these two diseases are to be differentiated from one another or are to be considered identical." This remark is evidently inspired by a hasty reading of Freud's monograph. The latter author finds it strange that in spite of Little's excellent descriptions "no distinction is drawn in Anglo-American literature between general rigidity and bilateral cerebral palsies." "German and French authors are guilty of another error," Freud continues, "in failing to recognize the gradual transition between rigidity and paralysis"... " Little's hemiplegic spasmo-paralysis is merely a spastic hemiplegia."

The apparent ignorance of English and American authors is accounted for by the fact that they soon recognized that there was no radical distinction between the types described by Little and the cerebral diplegias which we have learned to know in every detail. Osler ${ }^{4}$ in his monograph, published in 1889 , recognized Little's merits, for he writes that he (Little) has contributed more than any one to the subject, and to him we owe in great part the accurate knowledge of the relation of the cases (of bilateral spastic hemiplegia) to abnormal parturition. In France, Osler adds, the cases of spastic rigidity are sometimes called Little's disease (p. 57). In my first study of cerebral palsies with Peterson, and in later writings, I have recognized Little's etiological group; it cannot,

"Grosz: Archiv f. Kinderheilkunde, 1897.

${ }^{3}$ Loc. cit., p. 23. Foot note.

The Cerebral Palsies of Children. Philadelphia, I889.

sachs and Peterson. Journal of Nervous and Mental Disease, Nay, 18 co. 
therefore, be fairly said that any of us was ignorant of Little's contributions; but, knowing them, we did not feel bound to indorse the conclusions which others have drawn from lis writings; nor did. we think it proper to establish "Little's Disease" as a clinical entity. There is some satisfaction that, in spite of the various insinuations that have been made, Freud has adopted our own point of view. His words are (p. 227): "We are forced, therefore, to the conclusion that Little's disease (so-called) cannot be accepted as a clinical entity, and the forms described under this heading must be classed with the diplegic types of infantile cerebral palsy." In spite of this concession, this author thinks it necessary, however, to retain the term "Little's clisease" for those cases in which Little's etiology is a prominent characteristic, and in which the clinical symptoms are in agreement with Little's description. Freud's position is not logical, and it will not, I fear, help to clear away the confusion that has arisen.

Among French authors there is also a tendency to depart from what I must consider to be the rational interpretation of these various spastic types of infantile palsies. Brissaud, ${ }^{6}$ for instance, defines Little's disease as "a congenital and spasmodic paraplegia of all four extremities, more marked in the lower, and affecting more particularly children born before term, characterized by convulsive phenomena or intellectual defects, and "susceptible, if not of a complete cure, at least of a progressive improvement." Brissaud has a special series of cases in mind which are familiar enough to all of us as spastic diplegias with slight. mental involvement. He considers them to be of cerebral origin, and accounts for the preponderance of the affection in the lower extremities by insisting that it is very likely that the region of the paracentral lobule, whence issue the pyramidal fibres destined for the lower extremities, has the poorest blood supply of all cortical areas. If the cor-

\footnotetext{
"Leçons sur les Maladies Nerveuses. Paris, 1895. P. i 10.
} 
tical circulation is slower in the paracentral lobule than in all the other areas of the Rolandic region, this will suffice to explain the nuarked arrest in development of the pyramidal fibres going to the lower extremities. In passing we may note that Raymond ${ }^{7}$ has in one of his latest publications placed himself in line with Freud and the American authors; he recognizes various types of spasmodic spinal paralyses, but thinks that the lines of demarcation are purely artificial. Van Gehuchten ${ }^{\mathrm{s}}$ in a series of articles published in 1896 , entitled " Faísceau pyramidal et Maladie de Little," has given a very ingenious explanation for certain cases of congenital spastic palsy, but has created some confusion by considering the spastic palsies occurring in children born before term as the sole representative of Little's disease, and by insisting that if there is any one thing that is characteristic of Little's disease, it is the complete absence of paralysis.

Availing himself of Flechsig's investigations, Van Gehuchten attempts to show that in the newborn child at full term the white fibres of the pyramidal tracts have not yet acquired their myelin sheaths, and, furthermore, that in children born at seven months, the pyramidal tracts do not yet contain axis cylinders, at least below the medulla oblongata; from which he draws the conclusion that the cases of "Little's alisease," so-called, are due to defective development of the lower portion of the pyramidal tracts.

If we were to ask in consideration of the preceding sumnuaries, What is Little's disease? the only just answer would be, whatever an author pleases to make it. The cases clescribed by the various writers have not even a common etiology, for in the cases described by Van Gehuchten, for instance, the asphyxia neonatorum, to which Little attached the greatest importance, plays no rôle whatever.

'Maladies du Système Nerveux, etc. Paris, 1894. P."4r3.

'Journal de Neurologie et d'Hypnology, June 5, I896. 
Before we decicle whether or not we shall reject the designation "Little's Disease," let me give you briefly a few extracts from the English author's writings, and I do this all the more willingly as it is evident that he has been quoted so often at second hand that it would be a mere matter of justice to revert to the original article. "I showed," says Little, " "that premature birth, difficult labors, mechanical injuries during parturition to head and neck where life has been saved, convulsions following the act of birth, were apt to be succeeded by a determinate affection of the limbs of the child which I designated, spastic rigidity of the limbs of new-born children, spastic rigidity from asphyxia neonatorum, and assimilated it to the trismus nascentium and the universal spastic rigidity sometimes produced at later periods of existence." Again he says: "I am justified in regarding the dissections of Hecker and Weber as confirmatory of the opinion . . . that asphyxia neonatorum through resulting injury to nervous centres is the cause of the commonest contractions which originate at the moment of birth, namely more or less spastic rigidity and sometimes of paralytic contraction." Please note this reference to paralysis. The existence of such is also insisted upon again and again when he refers to the greater weakness of muscles of the dorsal aspect of the trunk, to the nuuscles of speech commonly involved. He states especially that mental changes occur from the "slightest inpairment which the parent unwillingly acknowledges and fails to perceive rup to entire imbecility." $\mathrm{He}$ also believes that the spastic rigidity which follows asphyxia at birth is due to lesion of the spinal cord and not to lesion of the brain or medulla oblongata; that from some cause this nervous centre suffers most often from the asphyxia, or least frequently recovers its integrity. In view of these conclusions of Little, it is well to note that he records but two autopsies in more than sixty cases,

${ }^{2}$ Transactions of the London Obstetrical Society, Vol. III., 1862. 
and that in these two there were distinct cerebral lesions. In one of these cases it is stated that the cord was not examined. Little, evidently, disregarded the post-mortem results and built up his views of the spinal origin of these spastic troubles on the clinical resemblance between these cases and those of spastic paraplegia in the adult. A careful reading of Little's articles leads to the following conclusions:-

I. He was struck by the prominence of rigidity and spastic contractures, but he acknowledges the occurrence of paralysis. On one of tlie two plates accompanying his article he pictures a child which he describes as "more paralytic than spastic."

2. The lower extremities are generally more affected than the upper, but this list of cases includes children with hemiplegia, with complete and incomplete diplegia, and sone with paraplegia.

3. He ascribes these spastic palsies to difficulties during parturition and, above all, to asphyxia neonatorum. Moreover, it is particularly to be noted that in children prematurely born he ascribed the trouble not to defective development of tracts (of which he could have known almost nothing), but to the asphyxia which often occurs at the moment of birth when the change is made from placental to pulmonary circulation.

If we compare Little's contributions to this subject with the German and French writings previously allucied to, it hecomes evident that his views have been considerably distorted, or at least modified, and that a number of. recent investigators have tried to make the conclusions of more recent studies harmonize with views expressed fully thirty years ago. I have as much veneration as any one for the good work done by our predecessors, but we must not allow such veneration to be the cause of incalculable confusion. The researches on infantile cerebral palsies, published botli here and abroad during the last 
decade, have shown that the distribution of the paralysis, whether heiniplegic, diplegic, or paraplegic, was not a sufficient basis for differentiation; that such differences as existed were due to the varying extent to which one or both motor tracts were involved, and that it was wiser to divide all cases of spastic palsies in children into three large groups. First, those due to prenatal causes, including defective development; second, those due to diffculties during parturition; and third, the acquired cerebral palsies coming on during the first few years of life. This classification upon which I have insisted in previous writings, has been indorsed by Freud in his latest monograph. With the acute cases we are not concerned at the present time, but the groups one and two include cases like those described by Lit tle, and the question therefore is, whether we shall surrender the advance made by establishing these separate groups, or whether we shall cling to this division and surrender the term "Little's clisease."

To corroborate the impressions formed in former years, I have asked Dr. Onuf to examine the records of my clinic during the past few years, and to tabulate once more the " congenital,"' or more properly speaking, the." prenatal" and "birth" cases, with a view to indorsing or refuting the various doctrines which have been more recently promulgated. Fifty records were examined; of these eight were rejected, because some of the data had not been obtained with sufficient accuracy.

In these tables only such facts are given as bear upon the subject immediately under discussion.

From the subjoined table we may infer that premature birth, instrumental delivery, protracted labor, asphyxia, at the time of birth-any one or several of these conditions combined may be the cause of spastic hemiplegia, diplegia or paraplegia. Asphyxia neonatorum is an important etiological factor, but it does not overshadow all other causative agencies, as Little thought. Paraplegias cannot 


\section{SUMMARY OF 42 CASES OF PRENATAL AND BIRTH PALSIES.}

\begin{tabular}{|c|c|c|c|c|c|}
\hline $\begin{array}{l}\text { SEX \& } \\
\text { AGE. }\end{array}$ & TERM. & $\begin{array}{l}\text { MANNER } \\
\text { OF BIRTH. }\end{array}$ & $\begin{array}{l}\text { FORM OF } \\
\text { PALSY. }\end{array}$ & $\begin{array}{l}\text { MENTAL CON- } \\
\text { DITION. }\end{array}$ & REMARKS. \\
\hline $16 \mathrm{~F}$. & Full. & $\left\{\begin{array}{c}\text { Labor tedions, no } \\
\text { instruments. }\end{array}\right.$ & Spastic diplegia. & Excellent. & $\begin{array}{l}\text { Mother kicked } \\
\text { during 7th month } \\
\text { of liregnancy; no } \\
\text { convulsions in } \\
\text { child. }\end{array}$ \\
\hline $\begin{array}{l}\text { 2. } \mathrm{F} \text {. } \\
3 \mathrm{y} \text {. }\end{array}$ & Full. & Asphyxia. & $\begin{array}{c}\text { Spast:c diplegia, } \\
\text { co n v l s i v e } \\
\text { twitchings of } \\
\text { both sides of face. }\end{array}$ & $\begin{array}{l}\text { Fair, but no spe- } \\
\text { cial d evel op- } \\
\text { ment. }\end{array}$ & $\begin{array}{l}\text { Motlier had pneu- } \\
\text { monia at time of } \\
\text { birth. dying five } \\
\text { days later. }\end{array}$ \\
\hline $\begin{array}{l}\text { 3. } \mathrm{M} \text {. } \\
3 \mathrm{y} \text {. }\end{array}$ & Full. & $\begin{array}{l}\text { Difficult labor,as- } \\
\text { phyxiated (one } \\
\text { honr). }\end{array}$ & Paraplegia. & Feeble-minded. & $\begin{array}{l}\text { Marked hydro- } \\
\text { cephalus. }\end{array}$ \\
\hline $\begin{array}{l}\text { 4. } \mathrm{M} \text {. } \\
3 \mathrm{y} \text {. }\end{array}$ & Full. & Slow labor. & \begin{tabular}{|} 
Paraplegia, right \\
hand defective.
\end{tabular} & $\begin{array}{l}\text { Fait, has begun } \\
\text { to speak. }\end{array}$ & $\begin{array}{l}\text { Four convulsions } \\
\text { at age of } 2 \text { years, } \\
\text { beginning i } \\
\text { right hand. }\end{array}$ \\
\hline
\end{tabular}

5. M. 7 ms. Labor lasted two Paraplegia,cross$4 \mathrm{y}$. days, not diff- legged position. cuit.

6. F. Full. Instrumental de$3 y$. $6 \% / 2$

8. M. Full. Instrumental de, Cros $12 \mathrm{y}$

9.1/2

10. M. Full. Forceps,asphyxi-spastic para-

$\begin{aligned} & \text { 10. M. Full. Forceps,asphyxi-s pastic para- } \\ & \text { 21/2 y. } \\ & \text { ated. }\end{aligned}$
xI. M. Full.
Shoit labor, as- Spastic diplegia.
$16 \mathrm{~m}$. phyxiated. cross-legged po- sition.

12. M. Fúl1. sivery, tedious gression, para labor.

$3 \mathbf{y}$.

13. F.

Full. Normal, but no

Normal labo1.

$9 \mathrm{y}$

movements felt some weeks before birth.

I4. F. Full. Difficult la bor, Spastic diplegia.
shoulder presshoulder preseutation, forceps.

I5. F. Full. Sndden, after se- Spastic he mi-

$6 \mathrm{y}$.

เ6. $\mathrm{M}$.

$5 \mathrm{y}$.

Fi11. vere fright.

spastic paraplegia.

I7. M. Full. Protracted labor. I. hemiplegia. $3 \mathbf{y}$.

8. F. Fu11. Instrumental de-Spastic diplegia. $5 \mathrm{y}$. livery.
Imbecile. Child weighed 3 pounds at birth, left arm weak, converging strabismus.

Feeble-minded. 'Microcephalus, slight prognathism,gothic palate.

A ppareutly good. Frequent general couvulsions.

Feeble-minded. Cranial deform1ities, poor teeth, occasiollal convulsions.

Fair. Associated novements.

Idiocy. Convulsions when 8 days old, none since.

Backward (?), Did not cry uutil 12 days old.

Good.

Six weeks after bith convulsious.noepilepsy, hands weak.

Inibecile.

Epilepsy since age of two years.

Deficient.

Convulsions twice in two years.

Fair.

Fréquent convulsions of right arm.

Good, in spite of 'I wo convulsions at distinct nicro- age of 3 years, cephalus. congenital strabismus.

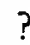
Gouvulslons during 48 hours after birth.

Fair. 


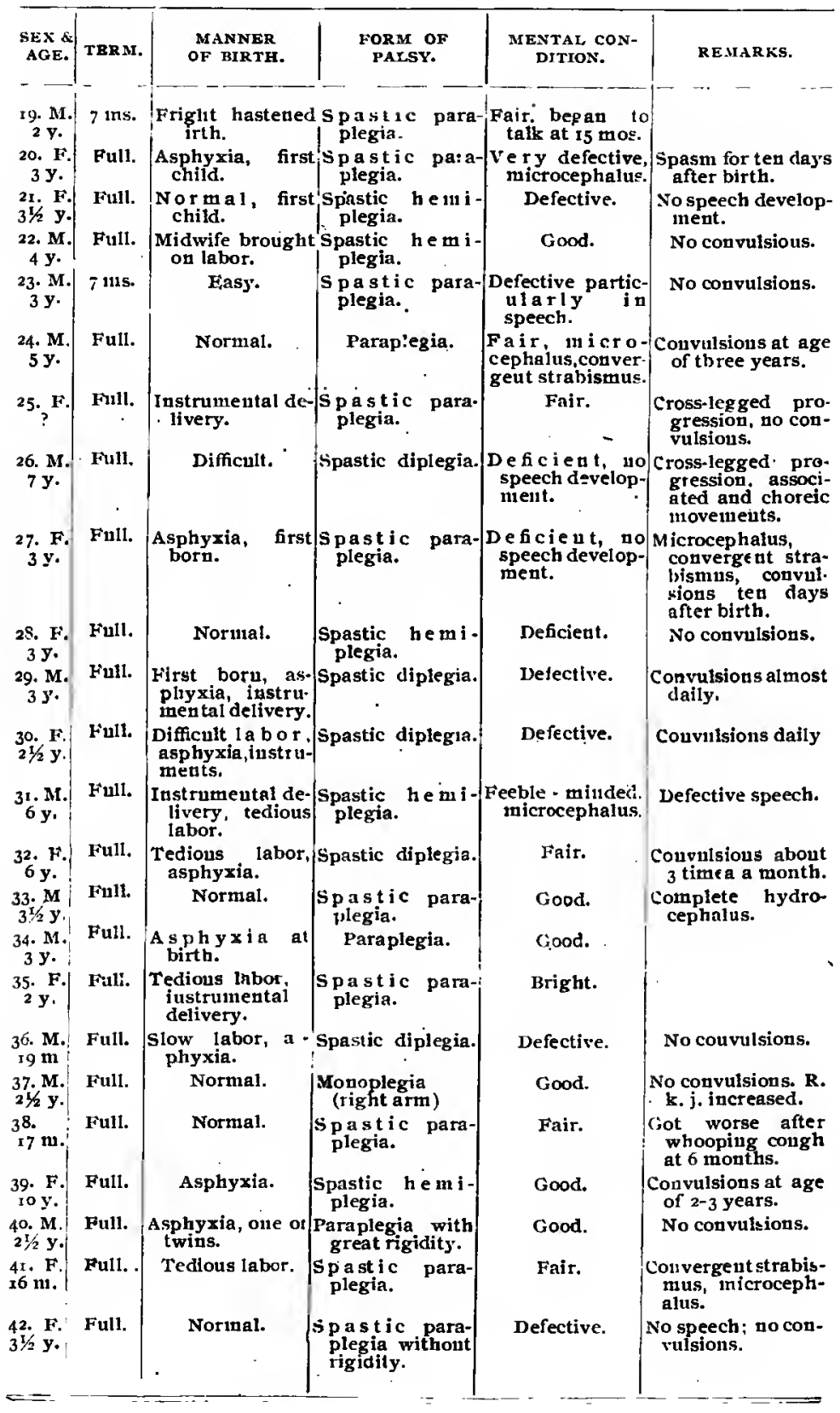


be attributed solely or even chiefly to an asphyxiated condition at birth, and it is entirely unwarranted to suppose that congenital spastic paraplegias are always, or chiefly, due to defective development of the pyramidal tracts in children born before full term, as Brissaud and Van Gehuchten would have us believe; for of the 42 cases of congenital cerebral palsies here recorded only three occurred in children born before full term.

If we are to give the name of Little's disease to conditions of spastic paraplegia in children prematurely born. we should be leaving out of account the very cases which I.ittle had in mind, namely, spastic diplegias and paraplegias due to asphyxia neonatorum; and if we were to include under this term only those cases in which there is some form of palsy due to abnormal delivery, we should exclude the important series of cases in which injury to the mother during pregnancy, some intercurrent disease of the mother, or a distinct hereditary factor, had exerted its influence over a child born at full term. In 23 of these 42 cases there was some abnormal condition of labor; ancl in seven others the child was born asphyxiated, although all other conditions were favorable. These facts seem to me fully to justify the conclusions drawn from previous studies. ${ }^{10}$

I am willing to concede that the rigidity is sometimes more striking than the paralysis, and can endorse the views of Dejerine that the difficulty in locomotion seems (at times) to be proportionate to the spasticity, but it is equally evident that the rigidity is almost invariably associated with some degree of paralysis. It is in entire keeping with our modern conceptions of the anatomy of the central nervous system that these conditions should now and then be due to defective developinent of the brain and of those tracts which descend from the brain into the spinal cord, and such defect of development may occur

\footnotetext{
"Sachs. Volkmann's Vorträge. 46. 47. 1892. P. 449. et seq.
} 
in children born at full term. This defect may be noticeable at birth, but if the arrest of development is not so marked, the clinical symptoms may not become apparent until some months or even years after birth. I cannot accept Van Gehuchten's explanation for the entire series of cases that are due to defective development, nor do I wish to separate the spinal portion of the pyramidal tract from its cerebral connections; and I believe that we must endeavor to enlarge our horizon by insisting that all cases with distinct defect of the cerebro-spinal motor system shall be brought under one heading, and that it matters little for purposes of classification whether the clinical symptoms in a given case be due to a porencephaly involving cortical motor areas, or to a defect in the development of the spinal portion of the pyramidal tract.

Van Gehuchten's explanation is not entirely satisfactory for several other reasons. First, it could not possibly explain the large number of congenital spastic cases that are associated with marked intellectual defect, and you may possibly remember that such defects have been shown by Peterson and $\mathrm{me}^{11}$ to occur in 7.1 per cent. of the diplegic, and about 82 per cent. of all paraplegic cases. Secondly, if this theory is to be accepted for the purely spastic cases without mental involvement, it would be difficult to explain why all seven months' children are not affected with spastic paralysis. In some children we must suppose that, although, they come into this world before time, the pyramidal tracts undergo normal evolution in the earlier period of extra-uterine life. In spastic children the normal evolution does not take place. Why this should be so, neither Van Gehuchten nor any one else is as yet able to explain. But I would not detract from the significance of the Belgian author's views, for I believe that he has given us the key to the relation between some of these congenital spastic palsies, and the hereditary spastic palsies

"Journal of Nervous and Mental Disease, May, 1890. 
of earlier years, and through these to the primary lateral scleroses which have been strongly established through the recent writings of Strümpell, Erb, and others. From this point of view these cases of defective development of the pyramidal tracts represent the graver and earlier forms of diseases which, when they occur later in life, we are accustomed to regard as evidence of the arrest of development and subsequent degeneration of various cerebrospinal systems.

To return to the "prenatal" cases, I wish to remark that the entire absence of convulsive seizures helps at times to differentiate them from those which are due to difficulties during labor and to meningeal hemorrhages resulting therefrom. A little difficulty arises, however, at times when there is both premature and protracted delivery. I have seen one very remarkable instance of this sort and have inferred from the closer examination of the brain and spinal cord of such a child that we may have a meningo-encephalitis as the result of the difficulties during parturition associated with defective development of the entire pyramiclal tracts. ${ }^{12}$ It is also well to observe that defective development of the pyramidal tract is not necessarily restricted to children born at seven or eight months, but may also occur in those at full term. And, bearing this fac $\hat{\imath}$ in mind, we need not expect to obtain the history of premature delivery in the cases of hereditary spastic paralysis or of tabes dorsal spasmodique occurring in older persons.

Enough has been said to show that if any further stuclies on these diseases are needed, they must be in the direction of a differentiation between, and a recognition of, the various forms of arrested cerebral and cerebrospinal development. It may be quite unnecessary to add that some advance has been made in this direction by establishing distinct types of family diplegias and other

\footnotetext{
.12 Sachs: Nervous Diseases of Children, p. 399.
} 
developinental defects occurring in various members of one and the same family. While we have every reason, therefore, to maintain the division into two distinct groups of spastic palsies in children, it would be a distinct step backward to drop this division for the sake of perpetuating an etiological factor which is present in some, but by no means in all of these cases. It may seem an ungracious lask to deprive an author of such fame as comes to him by connecting his name with a special form of disease. but if such a designation leads to confusion, it is clearly our duty to reject it. Little's services will for all times be remembered, as he was the first to point out clearly the importance of asphyxia neonatorum in the etiology of some spastic palsies of infancy. We shall not be injuring him by rejecting the designation "Little's Disease,". and since we have found that there is not sufficient clinical or anatomical evidence to designate any one group of cases by this name, I would suggest that we remove it from the classification of "prenatal " or "birth" palsies.

Dr. Peterson.-Having studied this subject with Dr. Sachs some years ago quite thoroughly, and having taken a great deal of interest in the matter since, I want to say a few words in regard to it. I fear I shall have to differ from Dr. Sachs to a certain extent. In the first place, in our studies we found that the more serious the injury to the brain, the greater was the extent of the paralysis, the more injury there was to the mental development, and more frequent was epilepsy. We found also that in hemiplegia there was not so much intellectual derect as in paraplegia, and not so much in paraplegia as in diplegia. Now, as occasionally we do meet with a case of double hemiplegia without any intellectual defect whatever, I do not see low that can be explained on the theory that it is a cerebral palsy.

Herbert R. Spencer, in the Westminster Hospital Reports several years ago, recorded a hundred and thirty autopsies in still-born children with visceral hemorrhages. Among these hundred and thirty cases were fifty-three of meningeal hemorrhage of the brain and thirty of hemorrhages into the spinal canal. It, therefore, seems to me that some of these cases of spastic paraplegia and diplegia, that we are accustomed to call cerebral, though they may present neither intellectual nor 
epileptic synptoms, might well be explained on the theory that there was a meningeal hemorrhage at birth into the spinal canal. These cases, however, seldom come to autopsy. In fact, I do not know of an autopsy on such a case in literature. But the name Little's disease has still its application to this restricted class of cases.

Dr. F. W. Putnam.-It seems to me that these developmental symptoms-or the lack of development-from deficiency of certain portions of the nervous system, will vary always in their symptomatology quite as a matter of accident. For instance, take the symptomatology of the disease called Friedreich's ataxia. At present I have three cases under consideration; the eldest patient is six years old, and has paralysis of both extremities, absence of knee jerk, and lack of mental development usually belonging to his age. His sister also has the absence of knee jerk, and also headache sometimes, but has not the same amount of paralysis; she is able to walk witlı a waddling gait, but falls down very easily. That child is four years old, and is able to walk and stand, and her mental development is better than that of her brother, who is six years old. She is able to talk better than he can, and carries out an order ur command better than he does. The child next youngest is about two and a half years old. It also has no knee jerks; has slight nystagmus; has not yet learned to creep; and does not show the usual mental development of a child of its age. Curiously, it appears as if there were a family influence there; an etiologic factor. The mother states that her pregnancies were ali marked by very long and prolonged nausea; that for the first seven months she nearly starved to death, as she expressed it. Whether or not that had any influence upon the nutrition of these children, or the development of their nervous system, is of course theoretical. It seens to me that we can see the phenomena of Friedreich's ataxia combined with symptoms indicating lack of cerebral development. There is a great deal of room for the classification of these defects manifested througl the disturbance of the various sensory phenomena.

Dr. Sachs.-I do not think Dr. Peterson can disagree with me at this late date, as I do not disagree with him. I was a little reserved in my statements in regard to the pathology of these conditions, and inasmuch as Dr. Peterson has suggested the possibility of a difference between us, I will simply say that I am inclined to think that some of these spastic palsies which we thought were cerebral may possibly be due to a spinal defect. But surely a large number of these cases are associated with defective mental conditions, and I must conclude that in them there is either an association of a cerebral with a spinal condition, or that the paraplegia was after all due to a cerebral lesion. The absence of the mental defect in some pa - 
tients can be explained by the fact that in those cases there is a strictly localized cerebral lesion, which need not necessarily be associated with any mental defect or any mental symptoms whatever. The change that has come over the views of most of the authors that have written upon these subjects of late is in the direction of conceding that there may be some cases that have a spinal origin; but I cannot yet believe that a majority of these cases are due to a spinal defect.

(To be continued)

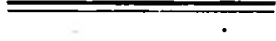

Encephalitis and Late Epilepsi. Jas. G. Kiernan, M.D. (Alienist and Neurologist, April, '97.)

Epilepsy occurring after 25, and that due to encephalitis, have points of special interest in common. Epilepsy following on the various forms of infantile encephalitis is more apt to be accompanied by trophic phenomena. It reacts badly to the bromides. Mental symptoms replace under the bromides the convulsions. The tendency to impairment of the circulatory innervation of the extremities is increased. The bromic dernatoses appear with great frequency. A nocturnal mental type, resembling somnambulism, takes the place often of the convulsion. Encephalitic epilepsy, while in many cases possibly Jacksonian at the outset, but too often becomes an epileptic constitution with all the phenomena of idiopathic epilepsy. After the age of 25, and most frequently between 35 and 40, in persons with no decided neurotic heredity, and in most of whom lues can be excluded, occurs an epilepsy which resembles that from encephalitis. As a rule, in these cases there has been a precedent period of nervous exhaustion attended by vertiginous states as its later development. These states are often preceded or followed by anomalous sensory disturbances compared by the pt. to "waves." There is a loss of, or dazed, consciousness, witl or without motor explosions. Some of these states. even when with consciousness, are attended by localized jerkings of groups of muscles. All of these phenomena are clearly due to toxins resultant on nerve exhaustion. Normally the toxins produced in the body are eliminated by various channels. When any of these emunctories are interfered with, the phenomena of auto-intoxication appear. The alterations are peculiarly suited for treatment of states due to toxin. By destruction of the toxin through stimulus of hepatic action and elimination, they prevent its accumulation, and the resultant phenomena. The alkaline bromides do not seem to exert this influence. Of late, metallic bromides have been (it is claimed) united in two compounds, the liquor arsen. auri, and liquor arsen. auri et hydrarg. These alternated weekly give, in the types mentioned, undeniably excellent results.

Freeman. 